\title{
What are the back beliefs of NHS employees, and does manual handling training influence them
}

\author{
D. NOLAN ET AL.
}

\author{
[AQ0] \\ David Nolan $^{\text {a Nicky Sharpe }}{ }^{\text {a Kieran O'Sullivan }}{ }^{b}$ [AQ1] DJohn Stephensonc Peter O'Sullivan ${ }^{d}$ \\ e [AQ1] DMike Lucock ${ }^{f} g$ \\ a. Sheffield Teaching Hospitals NHS Foundation Trust, Sheffield, United Kingdom of Great Britain and Northern Ireland; \\ b. School of Allied Health, University of Limerick, Limerick, Ireland; \\ c. Department of Health Sciences, University of Huddersfield, Huddersfield, United Kingdom of Great Britain and Northern Ireland; \\ d. School of Physiotherapy and Exercise Science, Curtin University, Perth, Australia; \\ e. Shenton Park, Body Logic Physiotherapy Clinic, Perth, Australia; \\ f. Centre for Applied Research in Health, University of Huddersfield, Huddersfield, United Kingdom of Great Britain and Northern \\ Ireland; \\ g. South West Yorkshire Partnership NHS Foundation Trust, Wakefield, United Kingdom of Great Britain and Northern Ireland
}

CONTACT David Nolan david.nolan@nhs.net Sheffield Teaching Hospitals NHS Foundation Trust, Sheffield, S10 2JF, United Kingdom of Great Britain and Northern Ireland

\begin{abstract}
Work absence due to back pain is best predicted by beliefs and attitudes. Lots of money is spent on training in the NHS trying to prevent back pain; this study explores the effect of that training on back pain beliefs.

151 NHS employees were surveyed using the Back Pain Attitudes Questionnaire before and after manual handling training. NHS employees had mixed beliefs. Before training, staff had positive beliefs about activity participation (8.25, SD 1.78), neutral beliefs about psychological influences (6.11, SD 2.51) and prognosis (6.34, SD 2.18), negative beliefs about relationship with injury $(5.26$, SD 2.09) and strongly negative beliefs about vulnerability of the back (2.81, SD 1.45). Training had a small negative effect $(-1.57$, SD $4.06 p<0.001)$ primarily through exacerbating beliefs regarding the vulnerability of the back $(-0.45$, SD $1.24, p<$ $0.001)$ and the relationship between pain and injury $(-0.80$, SD $1.83 p<0.001)$.

NHS employees hold many outdated views on back pain. The immediate effects of manual handling training based on the traditional paradigm of 'protect your back' appeared to make respondents slightly more cautious about using the spine; viewing it as easy to injure, that pain and damage may be linked, and slightly less optimistic about recovery.
\end{abstract}

Keywords: Low back pain ; movement and [AQ2]handling training ; back beliefs

\section{Introduction}

Lower back pain (LBP) is the leading cause of disability worldwide, and is associated with a large and growing burden for western societies [1]. The UK National Health Service (NHS) is no different, with LBP accounting for $20 \%$ of sickness absence, overall costing the UK economy £10 billion per year [2].

There is growing evidence that psychological factors are an important predictor of how people develop persistent LBP [3]. For example, low self-efficacy, pain catastrophising and fear avoidance beliefs regarding activity predict not recovering from LBP and not returning to work [4-8]. Furthermore, higher fear-avoidance beliefs are associated with longer work absence and slower return to full duties once back in work [9]. How long people with back pain are off work is important, as the chance of an employee ever returning to work decreases the longer they are absent $[10,11]$.

Manual handling $(\mathrm{MH})$ training is mandatory within the NHS, with the aim of preventing and minimising the impact of LBP. However, it is unclear if the psychological factors outlined above are considered during MH training. 
Our previous study showed that $\mathrm{MH}$ trainers have negative views about the back, perceiving it as vulnerable and in need of protection [12,13]. Similarly, the UK national guidelines around the delivery of MH training promote the need to protect the back [14]. Our previous study also showed that MH trainers strongly believed straight back lifting as safest, and that non-neutral lifting postures put the spine at risk. We wondered if these lifting beliefs are shared by NHS employees, despite there being no strong evidence for either of these beliefs, or that any particular lifting technique reduces LBP incidence [15].

It is possible that well-intentioned advice to protect the back while highlighting the risk of injury could exacerbate negative back beliefs among employees. Due to this concern, we wanted to investigate the LBP beliefs of NHS employees, and evaluate whether MH training influenced them.

Hence, this study had three questions:

- What are the LBP beliefs of NHS employees?

- Does MH training influence these beliefs?

- What lifting posture do employees think is safest, and does training influence this?

\section{Methods}

\section{Study design and setting}

This survey was performed in a hospital within an NHS trust in the UK. The study was designed as a single-session pre-post study. All employees have an induction day when they begin a new job. As part of this day, they receive a 30-minute $\mathrm{MH}$ training lecture that fulfils their mandatory training for the first year. The induction day was chosen for recruitment as it allowed convenient access to large numbers of employees, clinical and non-clinical, across all professions, experience and seniority in one venue.

\section{Ethics}

Local approvals were obtained from the Service Evaluation Unit, CEU Ref 8955. All participants were informed of the study with assurance of anonymity prior to volunteering. Consent was assumed by completion of the questionnaires

\section{Procedure}

Employees participating on induction days between 7 January 2019 and 4 March 2019 were asked to complete a survey pre- and post-MH training. Respondents were asked to state their age and gender, and whether they had suffered from back pain in the last 12 months. Back pain was defined as pain needing treatment, medication or a change in normal activities. Participants were asked: 'You are going to see four pictures of a subject about to lift a load from the floor. Pick which technique you consider the safest by placing a tick in the box next to the appropriate picture. Assume the load in the box is a weight that the subject finds heavy, but possible to lift'. Four pictures of a 37-year-old male with no history of LBP and adequate flexibility to assume these postures were used. This was the same format used in our previous publication [12]. Four sample lifting postures are shown in Figure 1, reflecting common lifting techniques: two with a straighter back, and two with a rounder back.

Figure 1. Four lifting postures, two with a rounder back (lift 1 and 3) and two with a straighter back (lift 2 and 4). 


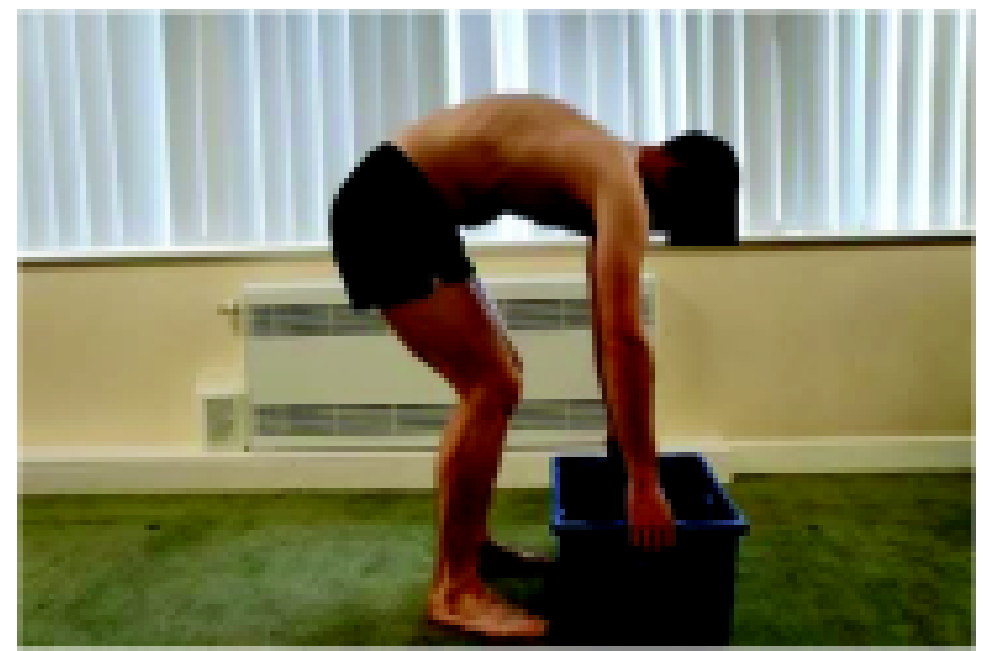

Lift 1

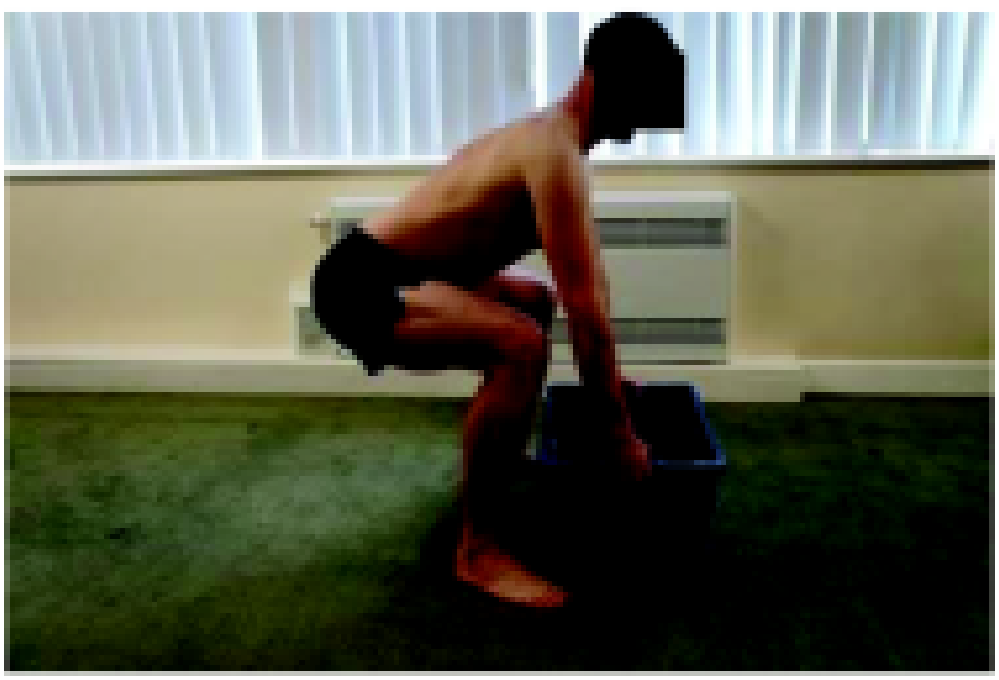

Lift 2

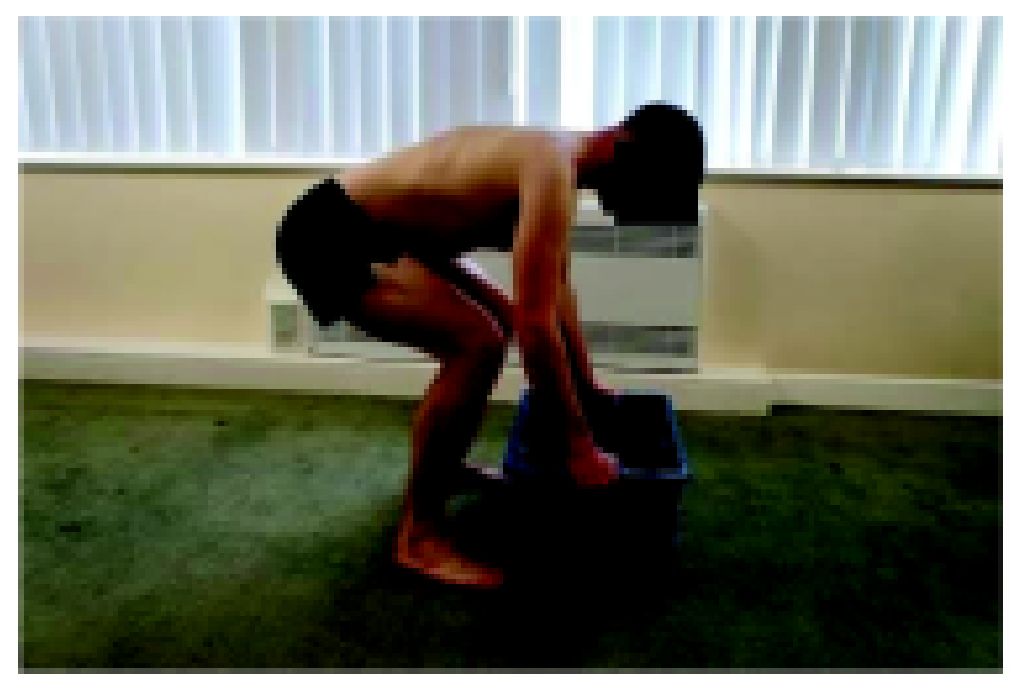

tifit 3

C Copyrights 2020

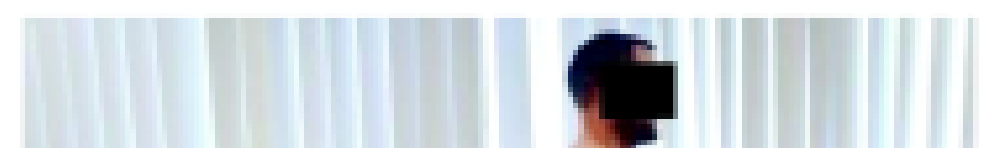


Respondents were then asked to complete the 10-item Back Pain Attitudes Questionnaire (Back-PAQ) to assess their back beliefs. This instrument comprises ten 5-point Likert items and is split into 5 domains, each comprising 2 items. High scores on each domain represent more positive beliefs, with some items reverse coded accordingly. Hence scores on the total scale could range from 10 to 50, with a neutral score being represented by a score of 30 ; and scores on individual sub-scales could range from 2 to 10 , with a neutral sub-scale score being represented by a score of 6 . This measure is reliable and has demonstrated convergent validity with the Tampa Scale of Kinesiophobia and the Fear Avoidance Beliefs Questionnaire [16]. The 10-item nature of the scale allowed for employees' attitudes and beliefs to be sampled quickly to avoid disruption to the day.

Directly after training, participants were re-surveyed with the Back-PAQ and asked the same lifting posture question, to see if their choice of safe lifting technique had changed

\section{Participants}

One hundred fifity-five successive employees were consented from the induction day training over a period of 8 weeks. There were no exclusion criteria and no refusals to participate. However, four people did not complete the initial questionnaire correctly, leaving 151 participants who correctly completed the pre-post survey.

\section{MH training}

Three different instructors gave 12 manual handling lectures over the eight weeks. They used the same 11 powerpoint slides with notes to ensure a consistent message (Table 1).

Table 1. Content of manual handling training.

\begin{tabular}{|c|c|}
\hline Slide & Theme of slide, taken from notes accompanying the power point \\
\hline Slide 1-3: Quiz & $\begin{array}{l}\text { Quiz about most frequently injured body part for NHS staff, most days lost } \\
\text { to musculoskeletal disorders (MSD) and what increases the risk of MSD (ex- } \\
\text { pected answer: bad posture and load) }\end{array}$ \\
\hline $\begin{array}{l}\text { Slide 4: What is movement and han- } \\
\text { dling? }\end{array}$ & Raise awareness of the impact of handling loads at home as well as work. \\
\hline Slide 5: Principles & $\begin{array}{l}\text { Principles of posture (maintain neutral spine, avoid twisting and bending } \\
\text { sideways with load); principles of risk assessment }\end{array}$ \\
\hline $\begin{array}{l}\text { Slide 6: Postural awareness, with pic- } \\
\text { tures to demonstrate }\end{array}$ & $\begin{array}{l}\text { Avoid slouching, avoid lordosis in standing, avoid poking your chin out, } \\
\text { avoid leaning on one leg and avoid hunched back and 'text neck'. }\end{array}$ \\
\hline $\begin{array}{l}\text { Slide 7: Avoid sustained top-heavy } \\
\text { posture, with picture of a woman bend- } \\
\text { ing with a round back and straight legs } \\
\text { back with a cross through it. }\end{array}$ & Advise not to use this posture, even with lighter loads. \\
\hline $\begin{array}{l}\text { Slide 8: Relative changes in load on } \\
\text { the disc. }\end{array}$ & $\begin{array}{l}\text { Nachemson et al., } 1966 \text { used to describe increased disc pressure in various } \\
\text { spinal postures, with increased load in forward leaning or flexed positions. }\end{array}$ \\
\hline Slide 9: Principles of movement & $\begin{array}{l}\text { Pictures to relax the knees, maintain stable base, relax shoulders, maintain a } \\
\text { neutral spine, not to grip, and raise head to keep spine neutral. }\end{array}$ \\
\hline $\begin{array}{l}\text { Slide 10: Practical involving maintain- } \\
\text { ing a stable base }\end{array}$ & $\begin{array}{l}\text { This was to get participants to relax knees to keep a stable base when being } \\
\text { pushed and pulled. }\end{array}$ \\
\hline $\begin{array}{l}\text { Slide 11: Risk assessment and local } \\
\text { policies and support. }\end{array}$ & \\
\hline
\end{tabular}

\section{Data analysis}


The sample was summarised descriptively. Data were assessed for the extent of, and patterns, of missingness. The extent of correlation between subscale scores was assessed on both measurement occasions. Pre-post analyses were conducted on the total scores of the Back-PAQ instrument, and on the individual sub-scale scores. The between-participants variables of age, gender and pre-existing LBP were tested by initial inclusion in repeated measures analysis of variance (RM-ANOVA) models. These variables were removed if found to be non-significant and not substantively related to the outcome measures, with models including pre- and post- Back-PAQ scores only being re-analysed using paired-samples $t$-testing or unadjusted RM-ANOVA as appropriate. Changes in proportions of participants who preferred a round, as opposed to straight, back pre- and post-training, was assessed using McNemar's test.

\section{Results}

Complete data were collected from 151 participants. 5 people did not report their gender, and 7 did not answer the back pain question. Participants characteristics are summarised in Table 2. Back-PAQ (pre- and post-) scores are summarised in Table 3.

Table 2. Participant characteristics.

\begin{tabular}{|l|l|}
\hline Variable & Frequency (valid \%) \\
\hline Gender & \\
\hline Male & $34(23.3 \%)$ \\
\hline Female & $112(76.7 \%)$ \\
\hline Pre-existing back pain status & \\
\hline No pain & $120(83.3 \%)$ \\
\hline Pain & $24(16.7 \%)$ \\
\hline Variable & Mean (SD) \\
\hline Age (years) & $35.0(11.6)$ \\
\hline
\end{tabular}

Table 3. Back PAQ scores and subscale scores pre- and post-manual handling training.

\begin{tabular}{|l|r|r|r|r|r|}
\hline Back-PAQ scores & $\begin{array}{c}\text { Pre-training- } \\
\text { mean (SD) }\end{array}$ & $\begin{array}{c}\text { Post-training- } \\
\text { mean (SD) }\end{array}$ & $\begin{array}{r}\text { Mean difference } \\
\text { (SD) }\end{array}$ & $p$-value & $\begin{array}{c}\text { Bonferonni corrected } \\
\text { 95\% CI }\end{array}$ \\
\hline Vulnerability sub-scale & $2.81(1.45)$ & $2.36(0.80)$ & $-0.45(1.24)$ & $<.001$ & $(-0.649,-0.251)$ \\
\hline $\begin{array}{l}\text { Relationship with injury } \\
\text { sub-scale }\end{array}$ & $5.26(2.09)$ & $4.46(2.15)$ & $-0.795(1.83)$ & $<.001$ & $(-1.09,-0.500)$ \\
\hline $\begin{array}{l}\text { Activity participation } \\
\text { sub-scale }\end{array}$ & $8.25(1.78)$ & $8.07(2.04)$ & $-0.179(1.33)$ & .101 & $(-0.393,0.035)$ \\
\hline $\begin{array}{l}\text { Psychological influen- } \\
\text { ces sub-scale }\end{array}$ & $6.11(2.51)$ & $6.32(2.65)$ & $0.212(2.04)$ & .204 & $(-0.116,0.540)$ \\
\hline Prognosis sub-scale & $6.34(2.18)$ & $5.99(2.67)$ & $-0.358(2.26)$ & .053 & $(-0.721,0.005)$ \\
\hline Total Back-PAQ score & $28.8(5.12)$ & $27.2(5.81)$ & $-1.57(4.06)$ & $<.001$ & $(0.917,2.22)$ \\
\hline
\end{tabular}

Correlational analysis revealed no substantive correlations between any of the Back-PAQ subscale scores at either measurement point: the absolute value of all pairwise correlations at either measurement point did not exceed 0.23 . A repeated-measures analysis of variance (RM-ANOVA) conducted on the data using the Back-PAQ Total scores outcome, and including the between-participants variables of Age, Gender and Pre-existing back pain found that none of these variables were statistically significant or substantively associated with the outcome. The between-participants variable was deleted from the model which was recast using within participants pre- and post-total scores only. A paired samples t-test revealed that the difference between mean pre-scores (28.8) and mean post-scores (27.2) of 1.57 
(SD for difference 4.06) was statistically significant at the $5 \%$ significance level $\left(t_{150}=4.75, p<0.001,95 \%\right.$ CI $0.917-$ 2.22). This indicated that back beliefs were overall slightly (1.57) more negative after training.

A doubly multivariate RM-ANOVA conducted on the data using the Back-PAQ subscale scores as outcome, and also including the between-participants variables, also found that none of these variables were statistically significant or substantively associated with the outcomes. The between-participants variable was again deleted from the model which was recast using within participants pre- and post- total scores only. An RM-ANOVA revealed that only two of the five sub-scale scores (vulnerability; relationship with injury) were significantly more negative after the training (Table 3).

\section{Lifting technique}

Pre-training, 16 participants preferred one of the round back technique (10.60\%). Post training, this was reduced to 9 participants preferring a round back technique (5.96\%). Hence the change in proportions was $4.64 \%$. Table 4 shows how people changed their views due to training.

Table 4. Lifting technique: Pre- and post-training safe lifting choice.

\begin{tabular}{|l|r|r|}
\hline Safe lift choice & Pre & Post \\
\hline 1 (round) & 0 & 0 \\
\hline 2 (straight) & 34 & 29 \\
\hline 3 (round) & 16 & 8 \\
\hline 4 (straight) & 101 & 114 \\
\hline
\end{tabular}

Table 5 illustrates that only eleven individuals (7.3\%) changed their opinion on safe lifting postures (from round to straight or vice versa) due to MH training. McNemar's test revealed evidence to reject the hypothesis of no difference in the proportion of participants preferring a round (or straight) lifting technique pre- and post-training $(p=0.035)$, with participants even more likely to prefer a straight back after training. A $95 \%$ confidence interval for the proportion of those changing their mind was given by $(0.39 \%, 8.88 \%)$.

Table 5. How people changed their views on what lifting choice was safest.

\begin{tabular}{|l|r|}
\hline Variable & Frequency \\
\hline Before round back (1 or 3); after round back (1 or 3) & 7 \\
\hline Before round back (1 or 3); after straight back (2 or 4) & 9 \\
\hline Before straight back (2 or 4); after round back (1 or 3) & 2 \\
\hline Before straight back (2 or 4$)$; after straight back (2 or 4) & 133 \\
\hline
\end{tabular}

\section{Discussion}

This was the first study to gather the LBP beliefs of employees in an NHS trust. The results show that employees had mixed LBP beliefs. Positively, they had good beliefs about staying active with LBP and relatively neutral beliefs about psychological influences and the prognosis of LBP. However, they had slightly negative beliefs about the relationship between pain and injury, and strongly negative beliefs about how vulnerable the back is to injury. This study also shows that current MH training at induction has a small negative effect on these beliefs, primarily through exacerbating existing negative beliefs regarding vulnerability of the back to injury and the relationship between pain and injury. The findings also highlight a strong bias among employees towards straight back postures being considered safest, and MH training exacerbated this biased towards straight back lifting postures, although the magnitude of people changing was small. 
The observed belief that staying active with LBP was helpful is encouraging. For over 30 years there have been consistent public health messages encouraging people to stay active with LBP, and this study adds further support that this message is now widely accepted. However, the back beliefs of employees surveyed showed they had strongly negative beliefs about how vulnerable the back is to injury. This is consistent with other studies that show the general population view the back as vulnerable and easy to injure [17-19]. These seem partially contradictory beliefs: it is important to be active, but the back is vulnerable to injury. What is of some concern is that the MH training worsened the belief that the back was vulnerable to injury, and that pain was associated with injury. This may not be a surprising result, as the general message in the MH training, which followed national guidelines, was to protect the back. There was a consistent message to avoid bending, twisting, and load bearing. Furthermore, data from the study of Nachemson et al. [20] was used to advise people against any bending or forward movement. The use of this data may have reinforced peoples' beliefs that the back was vulnerable, easy to injure and that non-neutral postures were unsafe. The effect of this training was small, but the general trend across most domains was negative. The immediate effect of the training did seem to make people slightly more cautious regarding their beliefs about using the spine, viewing it as easy to injure, that pain and damage may be linked, and slightly less optimistic about recovery. Although these changes were modest, they came about as a result of a brief lecture lasting only $30 \mathrm{~min}$. Furthermore, pre-existing beliefs around the vulnerably of the back were near to the ceiling of how negative they could be, so to make them worse is a cause for concern.

We found no difference in the beliefs between those without LBP and those who had an episode in the last year, although, the disability associated with LBP from our participants may have been low as all staff were fit to be in work, and only 24 were categorised as having LBP.

This study confirms that straight back lifting is overwhelmingly seen as the safest way to lift, with few people only 16 out of 151 - believing a rounder back was safest at baseline. MH training seemed to influenced this choice marginally, but these data should be interpreted with caution due to the small number of participants (11 of 151) who actually changed their preference. Nevertheless, the finding that people were even less likely to select a rounded posture post-training is noteworthy. Since a common theme in the MH training was that the back should not be rounded to lift, with such postures linked to increased disc loads and higher injury risk, this is unsurprising. These lifting beliefs of NHS employees match those we have previously reported among physiotherapists and MH advisors [12]. Interestingly though, there is no evidence that favours one lifting technique over another, and no evidence that lifting with a straighter back prevents injury [15]. Furthermore, in vivo studies show no clear link between spinal posture and disc pressure $[21,22]$. What has been shown though, is that those with LBP already lift with a straighter back than those without LBP [23]. It is unclear exactly why this is, but one hypothesis is that it is part of an unhelpful strategy to protect and the back rather than an attempt to minimise injury. While this needs further investigation, there is a building body of literature supporting that people with persistent LBP unhelpfully protect and guard their back, moving more cautiously than people without LBP $[24,25]$. Treatment aimed at giving people with LBP confidence to move less cautiously and encompassing the wider biopsychosocial interactions look promising [26-29], but robust replication studies in different contexts are needed.

Given these findings in NHS workers, and the data linking LBP with negative back pain beliefs, strategies to minimise the impact of LBP by targeting negative back pain beliefs among employees may be sensible, as providing population-based positive messages about LBP appears helpful [30]. With this in mind, other approaches of MH training with less emphasis on protecting the back are worth exploring. This is what we are now exploring within this Trust.

Since we only evaluated the immediate effects of the training, with no longer term follow-up, we do not know if any changes in beliefs were sustained. Furthermore, the survey was done in only one site. The participants were mostly younger women without back pain, or with back pain that was not stopping them from work, so the generalisability of these findings to different populations are unclear. Furthermore, this project was a local service evaluation and as such results cannot be generalised beyond our local population.

\section{Conclusion}

Employees at an NHS trust have mixed beliefs about LBP. While participants realised staying active was useful for LBP, they reported some adherent beliefs such as that the relationship between pain and injury was strong, and that the back was vulnerable to injury. A brief (30 min) MH training session - based on the common "protect your 
back' paradigm - appeared to make participants even more cautious about using the spine, and even more certain that straight back lifting was safest. This preliminary data suggests other MH training approaches are worth exploring.

\section{Disclosure statement}

No potential conflict of interest was reported by the author(s).

\section{References}

1. Hartvigsen J, Hancock MJ, Kongsted A, et al. What low back pain is and why we need to pay attention. Lancet. 2018;391(10137):2356-2367.

2. NHS employers. 2014. Back in work, introduction and key messages [Internet]. [cited 2019 Oct 17]. Available from: https://www.nhsemployers.org/-/media/Employers/Documents/Retain-and-improve/Back-in-Work/Back-inwork-part-1-Introduction-and-key-messages-web-final-25-March.pdf?.

3. Chen Y, Campbell P, Strauss VY, et al. Trajectories and predictors of the long-term course of low back pain: cohort study with 5-year follow-up. Pain. 2018;159(2):252-260.

4. Reme SE, Hagen EM, Eriksen HR. Expectations, perceptions, and physiotherapy predict prolonged sick leave in subacute low back pain. BMC Musculoskelet Disord. 2009;10(1):139

5. Jensen JN, Karpatschof B, Labriola M, et al. Do fear-avoidance beliefs play a role on the association between low back pain and sickness absence? A prospective cohort study among female health care workers. J Occup Environ Med. 2010;52(1):85-90.

6. Wertli MM, Rasmussen-Barr E, Held U, et al. Fear-avoidance beliefs-a moderator of treatment efficacy in patients with low back pain: a systematic review. Spine J. 2014;14(11):2658-2678.

7. Wertli MM, Eugster R, Held U, et al. Catastrophizing-a prognostic factor for outcome in patients with low back pain: a systematic review. Spine J. 2014;14(11):2639-2657.

8. Lee H, Hübscher M, Moseley GL, et al. How does pain lead to disability? A systematic review and meta-analysis of mediation studies in people with back and neck pain. Pain. 2015;156(6):988-997.

9. Staal JB, Hlobil H, Köke AJ, et al. Graded activity for workers with low back pain: who benefits most and how does it work? Arthritis Rheum. 2008;59(5):642-649.

10. Bendix AF, Bendix T, Haestrup C. Can it be predicted which patients with chronic low back pain should be offered tertiary rehabilitation in a functional restoration program? A search for demographic, socioeconomic, and physical predictors. Spine. 1998;23(16):1775-1783.

11. Waddell G, Burton AK. Occupational health guidelines for the management of low back pain at work: evidence review. Occup Med. 2001;51(2):124-135.

12. Nolan D, O'Sullivan K, Stephenson J, et al. What do physiotherapists and manual handling advisors consider the safest lifting posture, and do back beliefs influence their choice? Musculoskelet Sci Pract. 2018;33:35-40.

13. Nolan D, O'Sullivan K, Stephenson J, et al. How do manual handling advisors and physiotherapists construct their back beliefs, and do safe lifting posture beliefs influence them? Musculoskelet Sci Pract. 2019;39:101-106.

14. NBE. Standards in manual handling [Internet]; 2010; [cited 2018 Oct 9]. Available from: http://www.nationalbackexchange.org/files/training_guidelines/training_guidelines.pdf

15. Verbeek JH, Martimo KP, Kuijer PPFM, et al. Proper manual handling techniques to prevent low back pain, a Cochrane systematic review. Work. 2012;41(Supplement 1):2299-2301.

16. Moran RW, Rushworth WM, Mason J. Investigation of four self-report instruments (FABT, TSK-HC, Back-PAQ, HC-PAIRS) to measure healthcare practitioners' attitudes and beliefs toward low back pain: reliability, convergent validity and survey of New Zealand osteopaths and manipulative physiotherapists. Musculoskelet Sci Pract.

2017;32:44-50.

(C) Copyrights 2020 
17. Moffett JAK, Newbronner E, Waddell G, et al. Public perceptions about low back pain and its management: a gap between expectations and reality? Health Expect. 2000;3(3):161-168.

18. Goubert L, Crombez G, De Bourdeaudhuij I. Low back pain, disability and back pain myths in a community sample: prevalence and interrelationships. Eur J Pain. 2004;8(4):385-394.

19. Darlow B, Perry M, Stanley J, et al. Cross-sectional survey of attitudes and beliefs about back pain in New Zealand. BMJ Open. 2014;4(5):e004725

20. Nachemson A. The load on lumbar disks in different positions of the body. Clin Orthopaed Related Res. 1966;45:107-122.

21. Kingma I, Faber GS, van Dieën JH. How to lift a box that is too large to fit between the knees. Ergonomics. 2010;53(10):1228-1238.

22. Dreischarf M, Rohlmann A, Graichen F, et al. In vivo loads on a vertebral body replacement during different lifting techniques. J Biomech. 2016;49(6):890-895.

23. )Nolan D, O'Sullivan K, Newton C, et al. Are there differences in lifting technique between those with and without low back pain? A systematic review. Scand J Pain. 2020;20(2):215-227.

24. Geisser ME, Haig AJ, Wallbom AS, et al. Pain-related fear, lumbar flexion, and dynamic EMG among persons with chronic musculoskeletal low back pain. Clin J Pain. 2004;20(2):61-69.

25. Laird RA, Gilbert J, Kent P, et al. Comparing lumbo-pelvic kinematics in people with and without back pain: a systematic review and meta-analysis. BMC Musculoskelet Disord. 2014;15(1):229

26. Brox JI, Sørensen R, Friis A, et al. Randomized clinical trial of lumbar instrumented fusion and cognitive intervention and exercises in patients with chronic low back pain and disc degeneration. Spine. 2003;28(17):1913-1921.

27. Brox JI, Reikerås O, Nygaard Ø, et al. Lumbar instrumented fusion compared with cognitive intervention and exercises in patients with chronic back pain after previous surgery for disc herniation: a prospective randomized controlled study. Pain. 2006;122(1-2):145-155.

28. Vibe Fersum K, O'Sullivan P, Skouen JS, et al. Efficacy of classification-based cognitive functional therapy in patients with non-specific chronic low back pain: a randomized controlled trial. EJP. 2013;17(6):916-928.

29. O'Keeffe M, O'Sullivan P, Purtill H, et al. Cognitive functional therapy compared with a group-based exercise and education intervention for chronic low back pain: a multicentre randomised controlled trial (RCT). Br J Sports Med. 2020;54(13):782-789.

30. Buchbinder R, Jolley D, Wyatt M. Population based intervention to change back pain beliefs and disability: three part evaluation. BMJ. 2001;322(7301):1516-1520.

\section{AUthor QUeries}

Query: AQ0: Please review the table of contributors below and confirm that the first and last names are structured correctly and that the authors are listed in the correct order of contribution. This check is to ensure that your names will appear correctly online and when the article is indexed.

\begin{tabular}{|c|c|c|c|}
\hline Sequence & Prefix Given name(s) & Surname & Suffix \\
\hline 1 & David & Nolan & \\
\hline 2 & Nicky & Sharpe & \\
\hline 3 & Kieran & O'Sullivan & \\
\hline 4 & John & Stephenson & \\
\hline 5 & Peter & O'Sullivan & \\
\hline 6 & Mike & Lucock & \\
\hline
\end{tabular}




\section{Author Response: Ok}

Query: AQ1: Please note that the ORCID section has been created from information supplied with your manuscript submission/CATS. Please correct if this is inaccurate.

Author Response: Ok

Query: AQ2: Please note that the journal requires a minimum of 5-7 keywords. Please insert additional keywords accordingly.

Author Response: lifting; posture 